\title{
Manifestações públicas no território estadual de Minas Gerais
}

\author{
Supremo Tribunal Federal (STF)
}

\section{Reclamação 15.887 Minas Gerais}

Relator : Min. Luiz Fux

Reclte.(s) : Sindicato Único dos Trabalhadores em Educação de Minas Gerais - Sind-UTE/MG

Adv.(a/s) : Luís André de Araújo Vasconcelos e Outro(a/s)

Recldo.(a/s) : Tribunal de Justiça do Estado de Minas Gerais

Adv.(a/s) : : Sem Representação nos Autos

Intdo.(a/s) : Estado de Minas Gerais

Proc.(a/s)(es) : Advogado-geral do Estado de Minas Gerais

DECISÃO: Trata-se de reclamação, aparelhada com pedido liminar, ajuizada pelo Sindicato Único dos Trabalhadores em Educação de Minas Gerais SInd-UTE, em face de ato do Tribunal de Justiça do Estado de Minas Gerais, que teria supostamente desafiado a autoridade da decisão proferida por esta Suprema Corte nos autos da ADI n⿳⺈ 1.969-4/DF, rel. Min. Ricardo Lewandowski.

Em síntese, aduz que a decisão reclamada, ao determinar liminarmente que o Reclamante se abstivesse de realizar manifestações em vias e logradouros públicos em qualquer parte do território estadual (Ação Cautelar no 1.0000.13.041148-1/000 ajuizada pelo Estado de Minas Gerais), restringiu substancialmente o conteúdo do direito fundamental de livre manifestação do pensamento (CRFB/88, art. 5ํㅡ. IV) e de reunião (CRFB/88, art. 5o, XVI), nos balizamentos feitos pela Corte na ADI no 1.969-4/DF, rel. Min. Ricardo Lewandowski. Ademais, assevera que o acórdão paradigma assentou que as 
limitações ao direito de reunião somente poderiam ser veiculadas por lei em sentido formal, e desde que observado o núcleo intangível do aludido direito fundamental, o que in casu não teria ocorrido. Afirma, ainda, que a decisão judicial nega vigência ao direito de reunião e de manifestação de pensamento, restabelecendo os ideais autoritários do regime militar.

É o relatório suficiente. Decido.

In casu, articula o Reclamante que o decisum reclamado, ao interditar liminarmente manifestações em vias e logradouros públicos dentro do Estado de Minas Gerais, desafiou a autoridade do acórdão proferido pelo Supremo Tribunal Federal, nos autos da ADI no 1.969/DF, rel. Min. Ricardo Lewandowski.

Antes, porém, de examinar se houve o desrespeito ao acórdão apontado como paradigma, é preciso verificar se estão presentes os pressupostos para o cabimento da reclamação.

A Reclamação, por expressa determinação constitucional, destina-se a preservar a competência desta Suprema Corte e garantir a autoridade de suas decisões, ex vi do art. 102, I, alínea $l$, além de salvaguardar o estrito cumprimento das súmulas vinculantes, nos termos do art. 103-A, §3º , da Constituição da República, incluído pela EC no 45/2004. Neste particular, reconheço que a jurisprudência desta Suprema Corte estabeleceu diversos condicionantes para a utilização da via reclamatória, de sorte a evitar o uso promíscuo do referido instrumento processual. Disso resulta (i) a impossibilidade de utilizar per saltum a Reclamação, suprimindo graus de jurisdição, (ii) a impossibilidade de se proceder a um elastério hermenêutico da competência desta Corte, por estarem definidas em um rol numerus clausus, e, ao que interessa ao presente caso, (iii) a observância da estrita aderência da controvérsia contida no ato reclamado e o conteúdo dos acórdãos desta Suprema Corte apontados como paradigma. E, no caso vertente, existe tal similitude, uma vez que, tanto no ato reclamado quanto no acórdão paradigma, a discussão gravita em torno da possibilidade de se proceder a restrições ao conteúdo da liberdade de reunião e de expressão em logradouros públicos, razão por que vislumbro a indispensável identidade material entre a questão de fundo debatida no caso vertente e aquela travada nos autos da ADI no 1.969/DF.

Conheço, pois, da reclamação e passo ao exame liminar de mérito.

No caso sub examine, a controvérsia travada nestes autos versa suposta ofensa ao conteúdo essencial do direito de reunião e de livre manifestação do

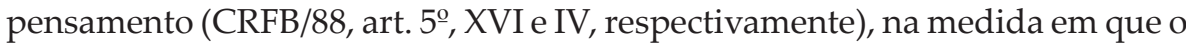
decisum reclamado teria interditado, em sede liminar, manifestações em vias e 
logradouros públicos dentro do Estado de Minas Gerais pelo ora Reclamante. Em sua decisão, o Desembargador do TJ/MG Barros Levenhagem ressaltou o caráter relativo do direito de reunião, cujo exercício encontrar-se-ia limitado pela liberdade de locomoção (CRFB/88, art. 5º, XV), pelo dever do Estado de prover segurança a toda a coletividade (CRFB/88, art. 144), pela restrição imposta ao direito de greve (Lei $\mathrm{n}^{-0} 7.783 / 89$, art. $6^{\circ}$, $\S^{\circ}{ }^{\circ}$ ) e pela necessidade de se observar a política urbana (Estatuto das Cidades, art. $2^{\circ}$ ). E, ao proceder a tal restrição, o Desembargador se distanciou dos balizamentos fixados por esta Suprema Corte na ADI nº 1.969/DF. Senão vejamos.

No acórdão paradigma da ADI no $1.969 / \mathrm{DF}$, a Corte foi instada a se pronunciar acerca da constitucionalidade de norma distrital (Decreto no 20.098/99), que proscrevia a realização de manifestações públicas, com a utilização de carros, aparelhos e objetos sonoros na Praça dos Três Poderes, Esplanada dos Ministérios e Praça do Buriti. Naquela assentada, o Tribunal julgou procedente o pedido formulado para declarar a inconstitucionalidade de norma asseverando que a restrição estabelecida ao direito de reunião não se compatibilizava com o postulado da proporcionalidade e seus subprincípios (adequação, necessidade e proporcionalidade em sentido estrito). Imperioso, neste ponto, trazer à colação excerto do voto do eminente relator Min. Ricardo Lewandowski, acolhido à unanimidade, que categoricamente afirmou "o Decreto distrital 20.098/99 simplesmente inviabiliza a liberdade de reunião e de manifestação, logo na Capital Federal, em especial na emblemática Praça dos Três Poderes, local aberto ao público, que, na concepção do genial arquiteto que a esboçou, constitui verdadeiro símbolo de liberdade e cidadania do povo brasileiro. Proibir a utilização de carros, aparelhos e objetos sonoros, nesse e em outros espaços públicos que o Decreto vergastado discrimina, inviabilizaria por completo a livre expressão do pensamento nas reuniões levadas a efeito nesses locais, porque as tornaria emudecidas, sem qualquer eficácia para os propósitos pretendidos. (...) Ademais, analisando-se a questão sob uma ótica pragmática, cumpre considerar que as reuniões devem ser, segundo a dicção constitucional, previamente comunicadas às autoridades competentes, que haverão de organizá-las de modo a não inviabilizar o fluxo de pessoas e veículos pelas vias públicas. Há que se ter em conta, por outro lado, que a utilização de aparelhos de som nas reuniões, que são limitadas no tempo, certamente não causará prejuízo irreparável àqueles que estão nas imediações da manifestação. (...) A restrição ao direito de reunião estabelecida pelo Decreto distrital 20.098/99, a toda a evidência, mostra-se inadequada, desnecessária e desproporcional quando confrontada com a vontade da Constituição (Wille zur Verfassung), que é, no presente caso, a permitir que todos os cidadãos possam reunir-se 
pacificamente para fins lícitos, expressando as suas opiniões livremente. Não vejo, portanto, à luz dos princípios da razoabilidade e da proporcionalidade, e em face do próprio texto da Carta Magna, como considerar hígida, do ponto de vista constitucional, a vedação a manifestações públicas que utilizem com a utilização de carros, aparelhos ou objetos sonoros na Praça dos Três Poderes, Esplanada dos Ministérios, Praça do Buriti e vias adjacentes.".

Com efeito, a identidade material reside precisamente no fato de que tanto a decisão reclamada quanto o acórdão paradigma cuidam da constitucionalidade da proibição ao exercício do direito de reunião e de livre manifestação de pensamento em espaços públicos que, por suas características sociais e históricas, permitam a maior propagação das ideias e opiniões manifestadas pelos diversos segmentos da sociedade civil.

Trata-se daquilo que o direito norte-americano intitulou como doutrina dos fóruns públicos (public-forum doctrine), segundo a qual uma sociedade livre deve criar uma plêiade de espaços nos quais se assegure, àqueles indivíduos que desejam se expressar, o direito de ter acesso aos lugares necessários para permitir a difusão da sua opinião entre as pessoas, notadamente aquelas áreas onde muitas delas se encontram (SUNSTEIN, Cass. Republic.com 2.0. New Jersey: Princeton University Press, 2007. p. 22-23).

Mas não é só. O direito de reunião consubstancia um componente indispensável à vida das pessoas e à própria existência de um substancial Estado Democrático de Direito. Conquanto a reunião de indivíduos em torno de determinados fins sociais tenha sempre existido no curso da história, é praticamente um consenso, como bem assinala o filósofo político canadense Will Kimlicka, que a vida associativa nos dias atuais encontra um solo fértil para as virtudes cívicas, ao mesmo tempo em que propicia uma base de sustentação para a construção de uma ordem democrática viável (KYMLICKA, Will. Ethnic Associations and Democratic Citizenship. In: GUTMANN, Amy. Freedom of Association. New Jersey: Princeton University, 1998. p. 177). Nesse cenário, a liberdade de reunião se apresenta como uma das liberdades básicas dos indivíduos, na formulação do filósofo John Rawls (RAWLS, John. As liberdades fundamentais e suas prioridades. In: Liberalismo Político. Trad. Dinah de Abreu Azevedo. 2. ed. São Paulo: Editora Ática, 2000. p. 347). Trata-se, à evidência, de um direito moral, que deve ser reconhecido e protegido, independentemente de juízos morais meramente contingentes ou majoritários em uma determinada comunidade. Justamente por isso, sob um enfoque filosófico, a liberdade de reunião ostenta um status especial, um "peso absoluto", com relação a razões de bem público, de cariz tipicamente 
utilitaristas, e a valores perfeccionistas, incompatíveis com o pluralismo existente nas sociedades contemporâneas. Com isso não se pretende afirmar que, sob o prisma jurídico-constitucional, o direito de reunião revista-se de caráter absoluto. Ao revés: o seu exercício pode encontrar-se limitado em virtude da colisão com o conteúdo de outros bens jurídicos de mesma estatura constitucional. Na realidade, o próprio constituinte originário previu expressamente uma restrição ao exercício do direito de reunião, quando decretado o Estado de Defesa (CRFB/88, art. 136, §1ํㅡ, I, alínea $b$ ).

É inegável, entretanto, a virtude cívica de movimentos sociais espontâneos que conclamem a participação ativa dos cidadãos na vida pública, de sorte a estimular a reflexão acerca de temas caros à ordem jurídica, política e econômica nacional. A democracia, longe de exercitar- se apenas e tão somente nas urnas, durante os pleitos eleitorais, pode e deve ser vivida contínua e ativamente pelo povo, por meio do debate, da crítica e da manifestação em torno de objetivos comuns.

Neste contexto, precisamente adverte o laureado economista indiano Amartya Sen que um grande número de ditadores no mundo tem conseguido gigantescas vitórias eleitorais, mesmo sem coerção evidente sobre o processo de votação, principalmente suprimindo a discussão pública e a liberdade de informação (SEN, Amartya. A ideia de justiça. Trad. Denise Bottman e Ricardo Doninelli Mendes. São Paulo: Companhia das Letras, 2011. p. 361), o que evidencia o liame indissociável entre a liberdade de expressão e a democracia. Considerando todos os benefícios sociais da argumentação pública, Amartya Sen comprova suas premissas com a constatação de que "nunca houve uma grande ocorrência de fome coletiva em uma democracia com eleições regulares, partidos de oposição, liberdade básica de expressão e uma imprensa relativamente livre (mesmo no caso de países muito pobres e em situação alimentar seriamente adversa)", sendo de rigor admitir, desse modo, que "as liberdades políticas e os direitos democráticos estão entre os 'componentes constitutivos' do desenvolvimento" (op. cit., p. 376 e 381).

Certo é que para a existência de uma democracia robusta este debate não pode cingir-se apenas aos mecanismos governamentais de captação da vontade popular, máxime quando a própria eficácia desses instrumentos é contestada no seio da sociedade. É preciso abrir os canais de participação popular para que os rumos da nação não sejam definidos exclusivamente ao talante dos governantes eleitos, estimulando que os destinatários das prestações estatais sejam copartícipes da formação da vontade política. No plano filosófico, Frederick Schauer nos recorda que a liberdade de expressão é protegida por 
ser o meio, por excelência, de chegar-se à verdade. O autor assenta a completa inaptidão do Governo para selecionar o que se deve entender por verdade, sendo que a obtenção desta somente é possível pelo mercado livre de ideias, qualificado pela livre troca de opiniões, pela liberdade de informação e pela liberdade de crítica (SCHAUER, Frederick. Free Speech: A Philosophical Enquiry. Cambridge University Press, 1982. p. 15-34).

O aumento dessa participação cívica, com uma intensa rede de interação entre os diferentes segmentos representativos da sociedade civil, estimula a produção do cognominado "capital social", formulado inicialmente por James Colmen e difundido na obra do cientista político de Harvard Robert Putnam (COLEMAN, James S. Social Capital in the Creation of Human Capital. American Journal of Sociology (Supplement), v. 94, p. S100-S101, 1988; PUTNAM, Robert. Bowling Alone: America's Declining Social Capital. Journal of Democracy, v. 6, n. 1, January 1995), indispensável para o adequado funcionamento e manutenção da estabilidade das instituições democráticas. O "capital social" é caracterizado pela confiança que os membros de um grupo demonstram em seus pares, o que aumenta as chances de realizarem seus projetos quando comparados a um grupo que careça desse grau de confiabilidade recíproca.

Deve-se valorizar, neste diapasão, a potencialidade democrática que as novas tecnologias representam para a formação do capital social, permitindo a formação de relações de confiança entre pessoas de diferentes lugares, crenças e inclinações políticas. Por meio da internet, a fronteira da tradicional dicotomia entre esquerda e direita se dilui para que a sociedade siga em frente, rumo à era da consciência social, do respeito aos direitos fundamentais, do desenvolvimento econômico responsável, sempre tendo como base e pressuposto a moralidade na gestão da coisa pública.

No caso sub examine, a insatisfação popular com as questões centrais da vida pública, inicialmente veiculada apenas em redes sociais na internet e que, por isso, já permeava o debate público em um espaço no qual não podia ser notada fisicamente - , tomou corpo e se transmudou em passeatas propositalmente realizadas em locais de grande significação e especial simbolismo, onde essas vozes, antes ocultas, podem ser percebidas com clareza pelos seus alvos, mercê de contribuírem para a edificação de um ambiente patriótico de reflexão sobre os rumos da nação. Além disso, é fato público e notório a anuência dos poderes constituídos ao movimento popular observado nas ruas, de manifestações em prol da democracia, da probidade e do bom emprego dos recursos públicos. A imprensa escrita e falada dá notícia 
das declarações de autoridades governamentais exaltando e chancelando o caráter legítimo e democrático de tais protestos, desde que sem vandalismo e depredação do patrimônio público e privado.

Cass Sunstein, referindo-se especificamente à liberdade de expressão oriunda da rede mundial de computadores, fecunda e própria da modernidade, como sói ocorrer atualmente no Brasil, deixa claro que esse direito não é absoluto, de modo que o Estado tem não apenas o poder, mas o dever de coibir excessos nocivos à vida social e que podem comprometer o próprio exercício, independente e informado, da livre manifestação. Nas palavras do professor de Harvard, uma infrutífera e reprovável tentativa de solicitar a alguém o cometimento de um crime, por exemplo, continua sendo uma incitação criminosa, ainda que se tente justificá-la com base em ideais democráticos (SUNSTEIN, Cass. Republic.com 2.0. New Jersey: Princeton University Press, 2007. p. 175-177).

Nesse mesmo campo, o Reitor da Yale Law School, Prof. Robert Post, divide a "palavra" e a "ação" para a definição do conteúdo da liberdade de expressão. Enquanto que um discurso proferido em uma multidão reunida em praça pública se enquadra na categoria "palavra", quebrar uma vidraça com um tijolo é uma "ação". Ambas as categorias de manifestações não são protegidas de maneira plena pela referida garantia constitucional. A liberdade de expressão, em ambos os casos, deve ser protegida apenas enquanto meio para a comunicação de ideias - a palavra não é acobertada pela garantia constitucional para veicular, por exemplo, um discurso de ódio. Mais ainda, não se pode admitir a barbárie a pretexto de transmitir uma mensagem ou proposta. Assim, ainda que alguém atire um tijolo contra uma vidraça para expressar que não concorda com certo ponto de vista ou atitude do proprietário do bem, e por mais clara que seja a mensagem retratada em tal ação, não é possível invocar a liberdade de expressão para excluir a prevenção e a repressão, civil e penal, contra o vandalismo (POST, Robert. Democracy, Expertise, and Academic Freedom. A First Amendment Jurisprudence for the Modern State. New Haven: Yale University Press, 2012. p. 2).

Ademais, ressoa absolutamente contraditório protestar contra a malversação de recursos públicos por meio da depredação de prédios e bens custeados e mantidos por toda a sociedade. Esse tipo de conduta não deve ser tolerado, seja pelo seu caráter violento, seja porque não é capaz de transmitir qualquer tipo de mensagem útil ao debate democrático.

Presente o fumus boni iuris quanto à liceidade das passeatas ordeiras, o periculum in mora se evidencia pelo fato de que manifestações têm sido 
realizadas diariamente em diversas cidades do país, de modo que a manutenção da eficácia da decisão impugnada tolhe injustificadamente o exercício do direito de reunião e de manifestação do pensamento por aqueles afetados pela ordem judicial, contrariando o quanto estabelecido pelo Supremo Tribunal Federal no julgamento da ADI no ${ }^{0}$ 1.969/DF.

Ex positis, concedo a liminar, cassando a decisão reclamada, nos termos do art. 21, V, do RISTF, porquanto consideradas legítimas as manifestações populares realizadas sem vandalismo, preservado o poder de polícia estatal na repressão de eventuais abusos.

Publique-se. Int.

Brasília, 19 de junho de 2013

\author{
Ministro Luiz Fux \\ Relator \\ Documento assinado digitalmente
}

